\title{
Long-Term Intermittent Exposure to High Altitude Elevates Asymmetric Dimethylarginine in First Exposed Young Adults
}

\author{
Nicole Lüneburg, ${ }^{1, *}$ Patricia Siques, ${ }^{2, *}$ Julio Brito, ${ }^{2, *}$ Juan José De La Cruz, ${ }^{3}$ \\ Fabiola León-Velarde, ${ }^{4}$ Juliane Hannemann, ${ }^{1}$ Cristian Ibanez, ${ }^{2}$ and Rainer H. Böger ${ }^{1}$
}

\begin{abstract}
Lüneburg, Nicole, Patricia Siques, Julio Brito, Juan José De La Cruz, Fabiola León-Velarde, Juliane Hannemann, Cristian Ibanez, and Rainer Böger. Long-term intermittent exposure to high altitude elevates asymmetric dimethylarginine in first exposed young adults. High Alt Med Biol. 18:226-233, 2017.- -Hypoxia-induced dysregulation of pulmonary and cerebral circulation may be related to an impaired nitric oxide (NO) pathway. We investigated the effect of chronic intermittent hypobaric hypoxia $(\mathrm{CIH})$ on metabolites of the NO pathway. We measured asymmetric and symmetric dimethylarginine (ADMA and SDMA) and monomethyl-L-arginine (L-NMMA) and assessed their associations with acclimatization in male draftees $(n=72)$ undergoing CIH shifts at altitude $(3550 \mathrm{~m})$ during 3 months. Sixteen Andean natives living at altitude $(3675 \mathrm{~m})$ (chronic hypobaric hypoxia $[\mathrm{CH}]$ ) were included for comparison. In CIH, ADMA and L-NMMA plasma concentrations increased from $1.14 \pm 0.04$ to $1.95 \pm 0.09 \mu \mathrm{mol} / \mathrm{L}$ (mean $\pm \mathrm{SE}$ ) and from $0.22 \pm 0.07$ to $0.39 \pm 0.03 \mu \mathrm{mol} / \mathrm{L}$, respectively, $(p<0.001$ for both) after 3 months, whereas SDMA did not change. The concentrations of ADMA and L-NMMA were higher in $\mathrm{CH}(3.48 \pm 0.07,0.53 \pm 0.08 \mu \mathrm{mol} / \mathrm{L} ; p<0.001)$ as compared with $\mathrm{CIH}$. In both $\mathrm{CIH}$ and $\mathrm{CH}$, ADMA correlated with hematocrit $\left(r^{2}=0.07, p<0.05 ; r^{2}=0.26 ; p<0.01\right)$. In CIH, an association of ADMA levels with poor acclimatization status was observed. We conclude that the endogenous NO synthase inhibitors, ADMA and L-NMMA, are elevated in hypoxia. This may contribute to impaired NO production at altitude and may also be predictive of altitude-associated health impairment.
\end{abstract}

Keywords: acclimatization; acute mountain sickness; ADMA; high altitude; intermittent hypoxia

\section{Introduction}

M INERS AND OTHER WORKERS adhering to varying shift regimens at high altitude are exposed to the unusual labor condition of chronic intermittent hypobaric hypoxia (CIH) (Richalet et al., 2002). Exposure to hypobaric hypoxia is generally well tolerated as acclimatization takes place. However, in a proportion of exposed individuals, low oxygen availability at altitude causes symptoms and may elicit diseases. Failure or loss of acclimatization may result in serious and fatal clinical manifestations, among which acute mountain sickness (AMS) in its several forms and acute or chronic increases of pulmonary artery pressure (Hackett and Roach, 2001; Richalet et al., 2002; Brito et al., 2007), followed by lung or cerebral edema (Penaloza and Arias-Stella, 2007) are the most commonly known. In subjects exposed to long-term $\mathrm{CIH}$, the persistence of AMS is as high as $50 \%$ and the prevalence of high-altitude pulmonary hypertension (HAPH) is $\sim 4 \%$ (Brito et al., 2007).

In populations permanently living at high altitude (chronic hypoxia $[\mathrm{CH}]), \mathrm{HAPH}$ and pathological erythrocytosis

\footnotetext{
${ }^{1}$ Department of Clinical Pharmacology and Toxicology, University Medical Center Hamburg-Eppendorf, Hamburg, Germany.

${ }^{2}$ Institute of Health Studies, Universidad Arturo Prat, Iquique, Chile.

${ }^{3}$ Department of Preventive Medicine and Public Health, Universidad Autónoma de Madrid, Madrid, Spain.

${ }^{4}$ Department of Biological and Physiological Sciences, Facultad de Ciencias y Filosofía/IIA, Universidad Peruana Cayetano Heredia, Lima, Perú.

*These authors contributed equally to this article.

(C) Nicole Lüneburg et al., 2017; Published by Mary Ann Liebert, Inc. This Open Access article is distributed under the terms of the Creative Commons Attribution Noncommercial License (http://creativecommons.org/licenses/by-nc/4.0/), which permits any noncommercial use, distribution, and reproduction in any medium, provided the original author(s) and the source are credited.
} 
(Monge's disease) are relevant problems, with prevalences varying between $15 \%$ and $20 \%$ (Leon-Velarde et al., 2005).

The vasodilator nitric oxide (NO) plays an important role in the regulation of oxygen delivery by local vasomotor control and in the central cardiovascular and respiratory responses to hypoxia (Semenza, 2011). Circulating NO has been shown to be higher in the Ladakhis, a high-altitude population of the Tibetan plateau, as compared with lowlanders (Ahsan et al., 2006). NO is produced by NO synthase (NOS), of which three isoforms are known (Michel and Feron, 1997). In the vasculature, the endothelial NOS (eNOS) plays a crucial role. It is regulated by several mechanisms and/or endogenous substances, such as methylarginines (Kittel and Maas, 2014).

Methylation of L-arginine residues in proteins (Nicholson et al., 2009) is a mechanism of post-translational protein modification. (Bedford and Richard, 2005). The products of such protein arginine methylation, monomethyl-L-arginine (L-NMMA), asymmetric and symmetric dimethylarginine (ADMA and SDMA), are endogenously present in the human body. ADMA and L-NMMA competitively inhibit NO synthesis from L-arginine, whereas SDMA does not (Vallance et al., 1992). ADMA has been identified as an important regulator of NO production in vivo (Böger et al., 2009). There is little published information on the possible role of ADMA in high altitude-induced hypobaric hypoxia in humans and its association with altitude diseases and acclimatization. Recently, one study in yaks demonstrated a low plasma ADMA concentration as a result of increased expression and activity of dimethylarginine dimethylaminohydrolase (DDAH), the enzyme that degrades ADMA (Mizuno et al., 2015). We have recently shown that ADMA is also increased in rats that are exposed to chronic intermittent hypoxia (Lüneburg et al., 2016). Moreover, a study in humans found that the occurrence of high-altitude pulmonary edema is associated with an enhanced vasoconstrictor activity due to an impaired NO pathway involving ADMA (Ali et al., 2012). However, changes over time of ADMA, L-NMMA, and SDMA, especially in long-term chronic intermittent hypoxia, have not yet been reported. For the first time, we performed a longitudinal study with young adults, non-natives and never exposed to high altitude $(3550 \mathrm{~m})$ undergoing $\mathrm{CIH}$ shifts, and followed them during a study period of 3 months. To compare different regimens of hypobaric hypoxia, we also included native Andean residents permanently living at high altitude as a group of people exposed to chronic hypobaric hypoxia $(\mathrm{CH})$.

\section{Methods}

\section{Study population}

Chronic intermittent hypobaric hypoxia $(\mathrm{CIH})$ group. One hundred male army draftees were included in our longitudinal study of $\mathrm{CIH}$. From these participants never exposed to high altitude earlier, 28 were lost at follow-up visits for nonmedical, that is, emotional and socioeconomic, reasons. The subjects' mean age was $18.9 \pm 0.9$ years, and $63 \%$ were smokers. Further characteristics describing the CIH group are provided in Table 1.

Chronic hypobaric hypoxia $(\mathrm{CH})$ group. A group of 16 male Andean natives living in Cariquima and Colchane (Chile; $3675 \mathrm{~m}$ ) were studied as a chronic hypobaric hypoxia $(\mathrm{CH})$ comparison group. The mean age of this $\mathrm{CH}$ group was $43.9 \pm 1.2$ years, and $19 \%$ were smokers. Further characteristics describing the $\mathrm{CIH}$ group are provided in Table 1.

\section{Study protocol}

$\mathrm{ClH}$ protocol. The army draftees were in a $\mathrm{CIH}$ shift regimen of 5 days at altitude $(3550 \mathrm{~m})$ and 2 days at sea level (SL) during the whole study period of 3 months. All army recruits had initially undergone physical examination elsewhere, the results of which had been considered healthy. Study participants adhered to a controlled diet $(3000 \mathrm{kcal}$ daily) and a defined daily exercise regimen (half an hour of mild effort walking at altitude and a 1-hour running exercise at SL) during the whole study period.

Measurements were taken on three defined study days: at baseline (before exposure to high altitude; M0), at month 1 (after 1 month of exposure to CIH; M1), and at month 3 (after

Table 1. Time Course of Physiological Variables for the Chronic Intermittent Hypoxia Group at Month 0 (Sea Level; M0), Month 1 (Altitude; M1), and Month 3 (Altitude; M3), AND The Chronic Hypoxia Group

\begin{tabular}{lcrrr}
\hline & \multicolumn{3}{c}{ CIH group } \\
\cline { 2 - 4 } Variables & \multicolumn{1}{c}{ MO } & M1 & M3 & CH group \\
\hline Age, years & $18.9 \pm 0.09$ & & $43.9 \pm 3.1$ \\
Years at altitude & 0 & & $42.4 \pm 3.3$ \\
Body mass index, \% & $23.6 \pm 0.4$ & $22.8 \pm 0.3$ & $22.9 \pm 0.3^{\mathrm{a}}$ & $25.4 \pm 0.3^{\mathrm{b}}$ \\
Systolic blood pressure, mmHg & $113.3 \pm 1.3$ & $112.2 \pm 1.2$ & $117.2 \pm 1.3^{\mathrm{a}}$ & $114.4 \pm 0.9^{\mathrm{c}}$ \\
Diastolic blood pressure, mmHg & $71.0 \pm 1.1$ & $69.1 \pm 0.9$ & $72.5 \pm 1.0^{\mathrm{d}}$ & $70.3^{\mathrm{a}} \pm .5^{\mathrm{c}}$ \\
Heart rate (bpm) & $77.4 \pm 1.5$ & $81.6 \pm 1.4$ & $84.1 \pm 1.6^{\mathrm{d}}$ & $75.7 \pm 0.1^{\mathrm{b}}$ \\
Oxygen saturation, \% & $98.8 \pm 0.1$ & $93.0 \pm 0.2$ & $91.6 \pm 0.3^{\mathrm{d}}$ & $90.3 \pm 0.3^{\mathrm{b}}$ \\
Hematocrit, \% & $44.3 \pm 0.3$ & $46.1 \pm 0.2$ & $46.3 \pm 0.3^{\mathrm{d}}$ & $54.6 \pm 0.4^{\mathrm{b}}$ \\
Hemoglobin, mL/dL & $14.6 \pm 0.1$ & $15.3 \pm 0.1$ & $15.3 \pm 0.1^{\mathrm{d}}$ & $17.8 \pm 0.9^{\mathrm{b}}$ \\
\hline
\end{tabular}

Values are mean $\pm \mathrm{SE}$.

${ }^{\mathrm{a}} p<0.01 \mathrm{M} 3$ versus M0.

${ }_{p} p<0.01 \mathrm{CH}$ versus all the $\mathrm{CIH}$ periods.

$p<0.01 \mathrm{CH}$ versus CIH M3.

d $p<0.001 \mathrm{M} 3$ versus M0.

$\mathrm{CH}$, chronic hypobaric hypoxia; $\mathrm{CIH}$, chronic intermittent hypobaric hypoxia. 
3 months of exposure to $\mathrm{CIH}$; M3). All measurements were performed early in the morning, after 8 hours of fasting. Baseline measurements (M0) were taken at SL, except the Lake Louise Score (LLS), which is a self-assessment test describing the extent of AMS at altitude (Roach et al., 1993). For altitude conditions (M1 and M3), physiological measurements and LLS were taken after one night's sleep on the first day of the corresponding shift, 18 hours from arrival at altitude.

$\mathrm{CH}$ protocol. All parameters were measured on one random study day at altitude, early in the morning after 8 hours of fasting. Study participants consumed their usual diet, and most of them were sedentary according to WHO criteria (Bull et al., 2009). Only healthy subjects after a medical assessment were included.

Written informed consent was obtained from all study participants. This study was approved by the Ethical Committee of Universidad Arturo Prat, Iquique, Chile.

\section{Variables measured}

Age (years), weight $(\mathrm{kg})$, height $(\mathrm{m})$, and smoking habits were recorded. Body mass index (BMI) was calculated as weight $(\mathrm{kg})$ divided by height $\left(\mathrm{m}^{2}\right)$. On each study day, systolic blood pressure (SBP, $\mathrm{mmHg}$ ), diastolic blood pressure (DBP, $\mathrm{mmHg}$ ), heart rate (HR, beats/min), and hemoglobin oxygen saturation $\left(\mathrm{SaO}_{2}, \%\right)$ were measured. SBP and DBP were measured on the right arm of each participant in the seating position after a 5-minute rest, using appropriately sized cuffs and calibrated standard mercury sphygmomanometers. HR was measured with an HR-100C Omron device (Omron ${ }^{\circledR}$, Healthcare Inc., Bethesda), and $\mathrm{SaO}_{2}$ was measured by using a pulse oximeter (POX050; Mediaid ${ }^{\circledR}$, Cerritos). The mean of two measurements separated by a 3-minute interval was taken as the valid determination for $\mathrm{BP}, \mathrm{HR}$, and $\mathrm{SaO}_{2}$ according to international guidelines.

At altitude, the LLS was assessed on each of the three study days (Roach et al., 1993); AMS was diagnosed clinically when headache and one or more other symptoms occurred (i.e., gastrointestinal symptoms, insomnia, dizziness, lassitude, or fatigue) and an LLS of $\geq 3$ was achieved. Severity was assessed according to the following score: mild (3-4), moderate (5-10), and severe (11-15) (Roach et al., 1993).

Venous blood samples were taken without blood stasis. At M0, M1, and M3, the following laboratory parameters were measured in the CIH group: hematocrit, hemoglobin, ADMA $\mu \mathrm{mol} / \mathrm{L}$, NNMA $\mu \mathrm{mol} / \mathrm{L}$, and SDMA $\mu \mathrm{mol} / \mathrm{L}$. The same parameters were assessed at one single occasion in the $\mathrm{CH}$ group. For the measurement of dimethylarginines, EDTA plasma was kept frozen at $-80^{\circ} \mathrm{C}$ until analysis. Hematocrit and hemoglobin were measured on the day of blood withdrawal by using an automatic hematological counter (Celldyn $3700^{\circledR}$, Tecnigen, Santiago, Chile).

\section{Measurement of dimethylarginines}

Mass spectrometric determination of ADMA, L-NMMA, and SDMA was performed as described elsewhere (Schwedhelm et al., 2005, 2007). In brief, $20 \mu \mathrm{L}$ aliquots of EDTA plasma were analyzed by using $96-$ well $0.22-\mu \mathrm{m}$ microfiltration plates (Multiscreen HTS ${ }^{\mathrm{TM}}$, Millipore, Molsheim, France) after addition of $100 \mu \mathrm{L}$ aliquots of a metha- nolic solution of 40 pmol $\left[{ }^{2} \mathrm{H}_{6}\right]$-ADMA (Santa Cruz, Dallas). After conversion to their butyl ester derivatives, analytes were quantified with a Varian 1200L Triple Quadrupole MS (Agilent Technologies, Santa Clara) in the positive electrospray ionization (ESI+) mode. For all biomarkers, the imprecisions for inter- and intra-assay variations were $<5.6 \%$ and $<5.4 \%$, respectively.

\section{Data analysis}

Data are given as mean $\pm \mathrm{SE}$ or \%, unless indicated otherwise. All variables except LLS were normally distributed (Kolmogorov-Smirnov test). Statistical differences were tested by analysis of variance (ANOVA) of repeated measures in the follow-up CIH group or by Student's $t$-test, except for not normally distributed variables, for which the Wilcoxon test was used. The chi-square test was used for the observation of proportional differences for independent samples, and the McNemar test was used for related samples. Pearson's correlation analyses were performed between quantitative variables. A combined variable "Poorly Acclimatized" was created for subjects who had altitude outcomes, AMS presence, plus $\mathrm{SaO}_{2}<89 \%$ at month 3 . Subsequently, a receiver operating characteristic (ROC) curve analysis was performed to test the ability of ADMA to discriminate and correctly classify, by the area under the curve (AUC), those poorly acclimatized, with its confidence intervals and sensitivity and specificity. A significance level was established at $p<0.05$. Data were analyzed by using the SPSS 17.0 statistical package (SPSS, Inc. ${ }^{\circledR}$, Chicago, IL).

\section{Results}

\section{Time course of physiological variables in $\mathrm{ClH}$}

We observed a slight reduction of $\mathrm{SaO}_{2}$ over time $(p<0.001)$. Hematocrit and hemoglobin increased from M0 to M1 and were maintained until M3 $(p<0.001)$ (Table 1). SBP was increased at M3 compared with baseline $(p<0.01$, Table 1), whereas DBP did not change. HR continuously increased over time at high altitude $(p<0.001)$.

\section{AMS assessment}

The mean LLS at M0 was $2.7 \pm 0.3$. The LLS as well as the incidence of AMS decreased over time $(p<0.01$ for both, Table 2), and no severe cases of AMS were observed in M3. No correlation with other variables was found.

Table 2. Lake Louise Score and Proportion of Acute Mountain Sickness in the Chronic

InTERMitTENT HyPOXIA GROUP AT MONTH 0 (M0), Month 1 (M1), AND Month 3 (M3)

\begin{tabular}{llccc}
\hline Variables & & M0 & M1 & M3 \\
\hline LLS & $\bar{X}$ & $2.7 \pm 0.3$ & $1.1 \pm 0.2^{\mathrm{a}}$ & $1.3 \pm 0.3^{\mathrm{a}}$ \\
AMS\% & Yes & $57(46-70)$ & $18(9-28)^{\mathrm{a}}$ & $23(12-33)^{\mathrm{a}}$ \\
\hline
\end{tabular}

Values for LLS are mean \pm SE.

${ }^{a}$ Differences among periods versus M0 $p<0.01$.

AMS, acute mountain sickness; LLS, Lake Louise score. 

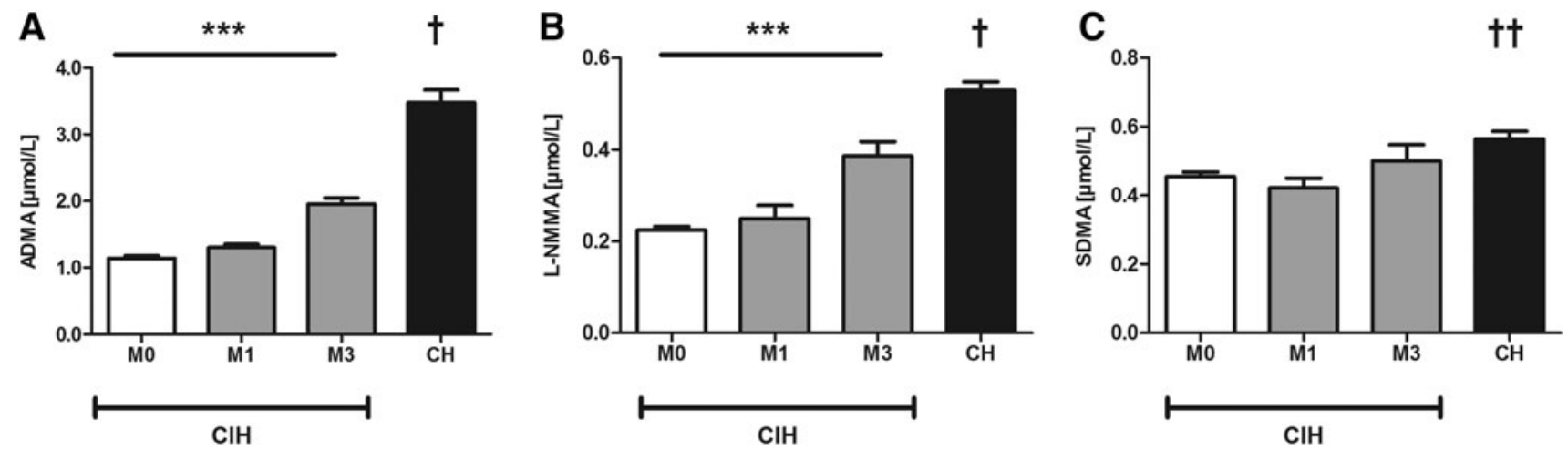

FIG. 1. Plasma concentrations of dimethylarginines in the CIH group ( $n=72)$ at month 0 (M0), month 1 (M1), and month 3 (M3), and in the CH group $(n=16)$; (A) ADMA ( $\mu \mathrm{mol} / \mathrm{L})$; (B) L-NMMA $(\mu \mathrm{mol} / \mathrm{L})$; and (C) SDMA $(\mu \mathrm{mol} / \mathrm{L})$. Values are mean \pm SE (standard error). $* * * p<0.001$ differences between the 3 months of follow-up at $\mathrm{CIH} ;{ }^{\dagger} p<0.001$ differences between $\mathrm{CH}$ and $\mathrm{M} 0, \mathrm{M} 1$, and $\mathrm{M} 3 ;{ }^{\dagger \dagger} p<0.01$ differences between $\mathrm{CH}$ and M0, M1. ADMA, asymmetric dimethylarginine; $\mathrm{CH}$, chronic hypobaric hypoxia; $\mathrm{CIH}$, chronic intermittent hypobaric hypoxia; L-NMMA, monomethyl-L-arginine; SDMA, symmetric dimethylarginine.

\section{Altitude native residents ( $\mathrm{CH}$ group)}

Mean $\mathrm{SaO}_{2}$ was slightly, but significantly lower $(90.3 \% \pm 0.3 \% ; p<0.01)$ than CIH M3. Hematocrit and hemoglobin were higher compared with $\mathrm{CIH}$ on all study days $(p<0.001$, Table 1). Systolic and DBP in CH were comparable to $\mathrm{CIH}$ at $\mathrm{M} 0$ and slightly lower than $\mathrm{CIH}$ at $\mathrm{M} 3$ $(p<0.01$, Table 1). HR was lower in $\mathrm{CH}$ than in $\mathrm{CIH}$ at $\mathrm{M} 3$ $(p<0.01)$.

\section{Dimethylarginines}

Plasma concentrations of both ADMA and L-NMMA were significantly elevated in $\mathrm{CIH}$ subjects at M1 and M3 compared with baseline (Fig. 1). ADMA progressively increased, reaching $80 \%$ higher levels at M3 $(1.11 \pm 0.04,1.26 \pm 0.05$, $1.95 \pm 0.09 \mu \mathrm{mol} / \mathrm{L}$; Fig. 1A). Also, with prolonged exposure time, an increasing proportion of subjects with ADMA levels that were higher than $2.0 \mu \mathrm{mol} / \mathrm{L}$ was observed (M0: $2 \%$; M1: 7\%; M3: $38 \%$ of study participants had ADMA levels higher than $2.0 \mu \mathrm{mol} / \mathrm{L})$. Likewise, L-NMMA increased by $60 \%$ at M3 $(0.22 \pm 0.08 ; 0.24 \pm 0.03 ; 0.39 \pm 0.03 \mu \mathrm{mol} / \mathrm{L}$; Fig. 1B), whereas SDMA concentrations remained unchanged $(0.45 \pm 0.02 \mu \mathrm{mol} / 1$ vs. $0.50 \pm 0.05 \mu \mathrm{mol} / \mathrm{L} ; p=\mathrm{NS})$ (Fig. 1C). In the $\mathrm{CH}$ group, ADMA and L-NMMA plasma concentrations were twofold higher compared with $\mathrm{CIH}$ at M0 (Fig. 1A, B). SDMA was only slightly higher in $\mathrm{CH}$ compared with $\mathrm{CIH}$ at $\mathrm{M} 0$ and $\mathrm{M} 1$, with no significant difference between $\mathrm{CH}$ and $\mathrm{CIH}$ at M3 (Fig. 1C).

In $\mathrm{CIH}$, there was a correlation between ADMA and hematocrit at altitude M3 $(R=0.28, p<0.05)$ (Fig. 2A). In the $\mathrm{CH}$ group, there was a strong correlation between ADMA and hematocrit $(R=0.66 ; p<0.01)$ (Fig. 2B). A positive correlation between hematocrit and SBP was found in both groups: $\mathrm{CIH}$ at $\mathrm{M} 1(R=0.34, p<0.001) ; \mathrm{CH}(R=0.51 ; p<0.01)$. Neither ADMA nor SDMA nor L-NMMA plasma levels correlated significantly with SBP, DBP, or $\mathrm{SaO}_{2}$.

At M3, ROC curve analysis (Fig. 3A) showed a strong association between ADMA concentration and poor acclimatization status (AUC 0.78, 95\% CI 0.60/0.95, $p<0.05$, Fig. $3 \mathrm{~B}$ ) showing that having ADMA $>2.7 \mu \mathrm{mol} / \mathrm{L}$ could be predictive of poor acclimatization.

\section{Discussion}

Our study has three major findings: (1) Three months of exposure to $\mathrm{CIH}$ causes a significant elevation of ADMA and L-NMMA plasma concentrations, whereas SDMA levels do not change significantly. Likewise, Andean native residents at high altitude have very high ADMA levels. (2) ADMA
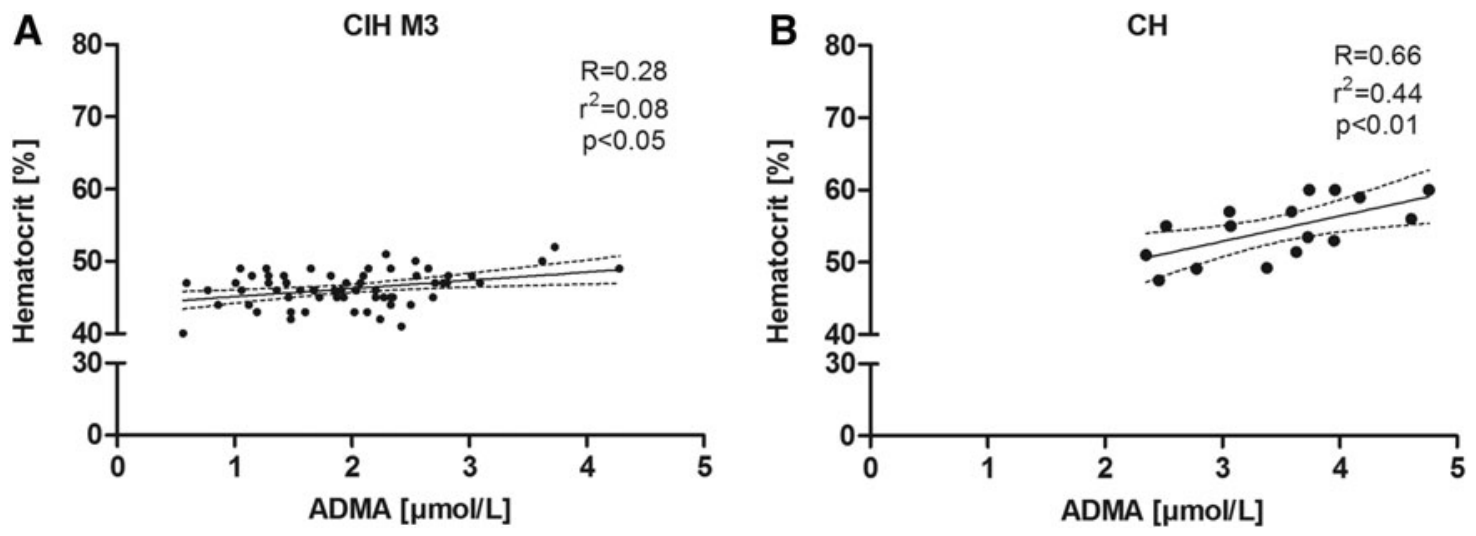

FIG. 2. Pearson's correlation analyses of ADMA ( $\mu \mathrm{mol} / \mathrm{L})$ and hematocrit $(\%)$ of $(\mathbf{A})$ the CIH group ( $n=72)$ at M3 and (B) the $\mathrm{CH}$ group $(n=16)$. Solid line: best-fit linear regression adjusted line; dashed line: $95 \%$ confidence interval. 


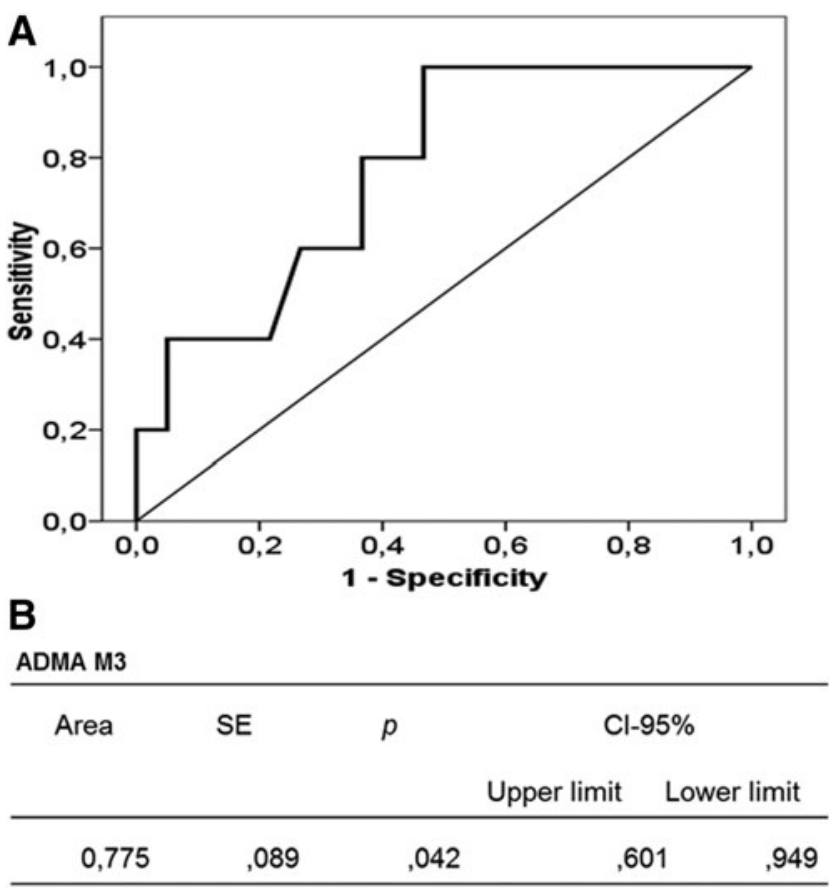

FIG. 3. ROC curve (A) and ROC analysis (B) of ADMA $(\mu \mathrm{mol} / \mathrm{L})$ and "poor acclimatization" (presence of AMS plus $\left.\mathrm{SaO}_{2}<89 \%\right)$ in the $\mathrm{CIH}$ group $(n=72)$ at month 3 (M3). AMS, acute mountain sickness; ROC, receiver operating characteristic.

plasma concentration is positively correlated with hematocrit in $\mathrm{CIH}$ as well as $\mathrm{CH}$. (3) In CIH, high ADMA concentration is related to poor acclimatization status.

For the first time, our study shows that altitude-associated hypoxia selectively increases the plasma concentrations of ADMA and L-NMMA, but not SDMA. High ADMA concentration is a strong independent predictor of mortality in patients with idiopathic pulmonary arterial hypertension (Kielstein et al., 2005). Increased ADMA and L-NMMA concentrations are associated with pulmonary hypertension (PH) in patients with sickle cell disease (Kato et al., 2009). Reduced bioavailability of NO under pathophysiological conditions may be caused by decreased expression of eNOS, inhibition of eNOS activity, or early oxidative degradation of NO by superoxide radicals (Millatt et al., 2003). As both ADMA and L-NMMA competitively inhibit eNOS, the studies cited earlier (Kielstein et al., 2005; Kato et al., 2009) suggest that impaired production of NO may be a major cause of endothelial dysfunction in $\mathrm{PH}$ and may contribute to the progression of this disease. Our study adds important information by demonstrating that high altitude significantly elevates ADMA and L-NMMA, but not SDMA. This effect was independent of the regimen of exposure ( $\mathrm{CIH}$ or $\mathrm{CH})$. Interestingly, mean ADMA plasma concentration was even higher in Andean natives who had spent their whole lives at high altitude than in the $\mathrm{CIH}$ subjects during their relatively short exposure during 3 months, although one might expect a higher level of adaptation in high-altitude residents. It might be interesting to know whether ADMA concentration is also high in other high-altitude populations, for example, Tibetan natives, in whom different adaptation mechanisms have been reported (Beall, 2006).
The results of our present clinical study are in line with our previous study in rats, in which we showed that ADMA, but not SDMA, is elevated in experimental $\mathrm{CIH}$ and $\mathrm{CH}$ (Lüneburg et al., 2016).

The main difference in the metabolism of ADMA, SDMA, and L-NMMA is that ADMA and L-NMMA are enzymatically cleared by dimethylarginine dimethylaminohydrolase (DDAH), whereas SDMA is not a DDAH substrate (Tran et al., 2003). Rather, SDMA is cleared by the enzyme AGXT2 (Lüneburg et al., 2014) and by renal excretion.

In our previous study in rats, we found decreased expression and activity of DDAH in hypoxia, which explains the selective elevation of the DDAH substrates, ADMA and LNMMA. The pattern of changes in biomarkers measured in the study presented here (elevation of ADMA and L-NMMA, no significant change in SDMA) suggests that dysregulation of DDAH may also occur in high altitude-induced hypoxia in humans. This hypothesis is supported by the study of Mizuno et al. (2015), who demonstrated reduced ADMA and enhanced DDAH activity in lungs of yaks - animals adapted to high altitude-as opposed to bovine. Furthermore, Ali et al. (2012) recently reported that elevation of ADMA, among other biomarkers, was associated with high-altitude pulmonary edema in first-time high-altitude sojourners. Although these authors measured ADMA at one single time point after first-time exposure to high altitude, we report here the time course of ADMA, NMMA, and SDMA plasma concentrations during 3 months of repeated exposure to intermittent hypoxia. In addition, Ali et al. (2012) reported a mean ADMA concentration of $1.9 \pm 0.8 \mu \mathrm{mol} / \mathrm{L}$ in Tibetan highaltitude native residents. By contrast, mean ADMA concentration in the Andean high-altitude residents was as high as $3.5 \pm 0.2 \mu \mathrm{mol} / \mathrm{L}$, suggesting the possibility of different molecular adaptation mechanisms between different populations living at high altitude. This interesting hypothesis needs to be corroborated in future studies.

The association between ADMA and hematocrit at $\mathrm{CIH}$ $\mathrm{M} 3$ and $\mathrm{CH}$, as found in our study, supports our hypothesis that the elevation of ADMA relates to hypoxia. An increase in hematocrit and a subsequent higher blood viscosity are expected phenomena that are related to hypoxia at high altitude (Zubieta-Calleja et al., 2007). Hematocrit has been demonstrated to be predictive of adaptation to altitude hypoxia (Reeves and Leon-Velarde, 2004; Siqués et al., 2006). However, this phenomenon is restricted to Andean populations. Other highland populations such as Tibetans or populations of Ethiopia do not show an increase in hematocrit at a similar altitude (Beall, 2006).

As opposed to acute hypoxia, where decreased systemic blood pressure is observed as a result of acute hypoxiainduced NO production in the endothelium (Cabel et al., 1994), we noted a tendency toward higher SBP in CIH. This observation is in line with the response to $\mathrm{CIH}$ caused by obstructive sleep apnea, where vasodilation by NO is overcome by other vasoconstrictor molecules such as endothelin-1 (Fletcher, 2001). An increase in blood pressure in individuals under chronic hypoxia at high altitude has repeatedly been demonstrated (Calbet, 2003; Siqués et al., 2006; Luks, 2009). Our results are consistent with these published data.

Insufficient adaptation to acute exposure to high altitude and persisting low arterial oxygen saturation are two major determinants of altitude-associated morbidity (Hackett and 
Roach, 2001; Richalet et al., 2002; Brito et al., 2007). We, therefore, defined "poor acclimatization" as the combination of persisting low $\mathrm{SaO}_{2}$ and the presence of AMS. For the first time, we describe here a tight association between high ADMA and "poor acclimatization," pointing to a predictive role of ADMA as a biomarker for altitude-associated morbidity. This finding might help to identify individuals who are susceptible to poor acclimatization based on their basal ADMA plasma concentration before their first exposure to altitude. The ADMA/DDAH pathway is tightly controlled, because it plays a crucial role in regulating NO bioavailability. Dysregulation of the ADMA/DDAH pathway has been reported in different hypoxia-associated chronic respiratory diseases such as asthma (Scott et al., 2011), chronic obstructive pulmonary disease (Scott et al., 2014), and obstructive sleep apnea syndrome (Barceló et al., 2009). We, therefore, hypothesize that downregulation of DDAH expression and/or activity, resulting in elevated ADMA concentration and subsequent loss of NO-dependent vasodilation, contributes to pulmonary ventilation/perfusion matching. When hypoxia becomes global instead of regional, dysregulation of the ADMA/DDAH pathway elicits systemic symptoms (e.g., elevated pulmonary or systemic blood pressure), thereby contributing to the progression of disease. Future prospective studies are needed to validate this hypothesis.

Finally, to reverse the altitude-associated dysregulation of the ADMA/DDAH-pathway, L-arginine supplementation or pharmaceutical upregulation of DDAH activity appears to be a promising option. Animal research strongly supports the use of L-arginine. In humans, pre-treatment with intravenous L-arginine decreases AMS score and improves arterial oxygen saturation at $4350 \mathrm{~m}$ (Schneider et al., 2001). In addition, L-arginine is able to improve exercise efficiency and tolerance during high-intensity exercise (Bailey et al., 2010). Finally, it elicits an improved short-term pulmonary vasodilatory response in patients with $\mathrm{PH}$ of various origins (Mehta et al., 1995). Since there is currently no therapeutically useable DDAH activator available, L-arginine supplementation seems to be the only therapeutic option at present.

\section{Limitations}

Our study included only male study participants. It is known that premenopausal women have lower ADMA plasma concentrations than age-matched men (Schulze et al., 2005; Schwedhelm et al., 2009). Therefore, it is unclear whether our results can be extended to women. Another limitation is the small number of native altitude residents. However, although blood samples were drawn on one random occasion in this control group, variability of all variables was low. We, therefore, believe that these data are meaningful. As we previously demonstrated that ADMA increases only slightly with age in men and women (Schulze et al., 2005; Schwedhelm et al., 2009), we propose that the large difference in ADMA concentration between $\mathrm{CIH}$ and $\mathrm{CH}$ may be, in major part, related to the duration of exposure to high altitude. The significant difference in BMI between $\mathrm{CIH}$ and $\mathrm{CH}$ groups may also have contributed to differences in ADMA plasma concentrations. We previously reported associations of ADMA and BMI in obese women with a median BMI of 28 (Reimann et al., 2007). Since the CH group had a mean BMI of 25, it cannot be classified as obese. In addition, it must be considered that the proportion of smokers in both cohorts, especially in the $\mathrm{CIH}$, is very high. Smoking impairs endothelial function; however, it tends to lower ADMA concentration, as previously demonstrated by our group (Maas et al., 2007). A combined effect of ADMA and smoking on endothelial function can, therefore, not be ruled out.

\section{Conclusion}

Chronic intermittent hypobaric hypoxia $(\mathrm{CIH})$ and chronic hypobaric hypoxia $(\mathrm{CH})$ lead to a large increase in ADMA and L-NMMA plasma concentrations, which may result in impaired NO availability. ADMA may play a dual, important role as (1) a predictor of poor acclimatization to hypoxia, and (2) a pathophysiological mediator involved in the incidence and progression of CIH-induced hypertension, AMS, and HAPH. As ADMA competes with L-arginine, the natural substrate of NO synthase, supplementation with L-arginine, as mainly demonstrated in animal experiments, may be one possibility to prevent diseases that are associated with high altitude.

\section{Acknowledgments}

The authors thank Mariola Kastner, Anna Steenpass, Sandra Maak, Stefany Ordenes, and Gabriela Lamas for their excellent technical assistance. This work was supported by grants from the FIC GORE-TARAPACA BIP 30434827-0, University Arturo Prat, and ALTMEDFIS-CYTED.

\section{Author Disclosure Statement}

No competing financial interests exist.

\section{References}

Ahsan A, Mohd G, Norboo T, Baig MA, and Pasha MA. (2006). Heterozygotes of NOS3 polymorphisms contribute to reduced nitrogen oxides in high-altitude pulmonary edema. Chest 130: 1511-1519.

Ali Z, Mishra A, Kumar R, Alam P, Pandey P, Ram R, Thinlas T, Mohammad G, and Pasha MA. (2012). Interactions among vascular-tone modulators contribute to high altitude pulmonary edema and augmented vasoreactivity in highlanders. PLoS One 7:e44049.

Bailey SJ, Winyard PG, Vanhatalo A, Blackwell JR, DiMenna FJ, Wilkerson DP, and Jones AM. (2010). Acute L-arginine supplementation reduces the $\mathrm{O} 2$ cost of moderate-intensity exercise and enhances high-intensity exercise tolerance. J Appl Physiol (1985) 109:1394-1403.

Barceló A, de la Peña M, Ayllón O, Vega-Agapito MV, Piérola J, Pérez G, González C, Alonso A, and Agustí AGN. (2009). Increased plasma levels of asymmetric dimethylarginine and soluble CD40 ligand in patients with sleep apnea. Respiration 77:85-90.

Beall CM. (2006). Andean, Tibetan, and Ethiopian patterns of adaptation to high-altitude hypoxia. Integr Comp Biol 46: $18-24$.

Bedford MT, and Richard S. (2005). Arginine methylation: An emerging regulator of protein function. Mol Cell 18:263-272.

Böger RH, Maas R, Schulze F, and Schwedhelm E. (2009). Asymmetric dimethylarginine (ADMA) as a prospective marker of cardiovascular disease and mortality-An update 
on patient populations with a wide range of cardiovascular risk. Pharmacol Res 60:481.

Brito J, Siques P, Leon-Velarde F, De La Cruz JJ, Lopez V, and Herruzo R. (2007). Chronic intermittent hypoxia at high altitude exposure for over 12 years: Assessment of hematological, cardiovascular, and renal effects. High Alt Med Biol 8:236-244.

Bull FC, Maslin TS, and Armstrong T. (2009). Global physical activity questionnaire (GPAQ): Nine country reliability and validity study. J Phys Act Health 6:790-804.

Cabel M, Smiesko V, and Johnson PC. (1994). Attenuation of blood flow-induced dilation in arterioles after muscle contraction. Am J Physiol Heart Circ Physiol 266:H2114H2121.

Calbet JA. (2003). Chronic hypoxia increases blood pressure and noradrenaline spillover in healthy humans. J Physiol 551: 379-386.

Fletcher EC. (2001). Invited review: Physiological consequences of intermittent hypoxia: Systemic blood pressure. J Appl Physiol (1985) 90:1600-1605.

Hackett PH, and Roach RC. (2001). High-altitude illness. N Engl J Med 345:107-114.

Kato GJ, Wang Z, Machado RF, Blackwelder WC, Taylor JG 6th, and Hazen SL. (2009). Endogenous nitric oxide synthase inhibitors in sickle cell disease: Abnormal levels and correlations with pulmonary hypertension, desaturation, haemolysis, organ dysfunction and death. $\mathrm{Br} \mathrm{J}$ Haematol 145:506-513.

Kielstein JT, Bode-Boger SM, Hesse G, Martens-Lobenhoffer J, Takacs A, Fliser D, and Hoeper MM. (2005). Asymmetrical dimethylarginine in idiopathic pulmonary arterial hypertension. Arterioscler Thromb Vasc Biol 25:14141418.

Kittel A, and Maas R. (2014). Pharmacology and clinical pharmacology of methylarginines used as inhibitors of nitric oxide synthases. Curr Pharm Des 20:3530-3547.

Leon-Velarde F, Maggiorini M, Reeves JT, Aldashev A, Asmus I, Bernardi L, Ge RL, Hackett P, Kobayashi T, Moore LG, et al. (2005). Consensus statement on chronic and subacute high altitude diseases. High Alt Med Biol 6:147-157.

Luks AM. (2009). Should travelers with hypertension adjust their medications when traveling to high altitude? High Alt Med Biol 10:11-15.

Lüneburg N, Lieb W, Zeller T, Chen MH, Maas R, Carter AM, Xanthakis V, Glazer NL, Schwedhelm E, Seshadri S, et al. (2014). Genome-wide association study of L-arginine and dimethylarginines reveals novel metabolic pathway for symmetric dimethylarginine. Circ Cardiovasc Genet 7:864872.

Lüneburg N, Siques P, Brito J, Arriaza K, Pena E, Klose H, Leon-Velarde F, and Böger RH. (2016). Long-term chronic intermittent hypobaric hypoxia in rats causes an imbalance in the asymmetric dimethylarginine/nitric oxide pathway and ROS activity: A possible synergistic mechanism for altitude pulmonary hypertension? Pulm Med 2016: 6578578.

Maas R, Schulze F, Baumert J, Lowel H, Hamraz K, Schwedhelm E, Koenig W, and Boger RH. (2007). Asymmetric dimethylarginine, smoking, and risk of coronary heart disease in apparently healthy men: Prospective analysis from the population-based monitoring of trends and determinants in cardiovascular disease/Kooperative Gesundheitsforschung in der Region Augsburg study and experimental data. Clin Chem 53:693-701.
Mehta S, Stewart DJ, Langleben D, and Levy RD. (1995). Short-term pulmonary vasodilation with L-arginine in pulmonary hypertension. Circulation 92:1539-1545.

Michel T, and Feron O. (1997). Nitric oxide synthases: Which, where, how, and why? J Clin Invest 100:2146-2152.

Millatt LJ, Whitley GS, Li D, Leiper JM, Siragy HM, Carey RM, and Johns RA. (2003). Evidence for dysregulation of dimethylarginine dimethylaminohydrolase $\mathrm{I}$ in chronic hypoxia-induced pulmonary hypertension. Circulation 108: 1493-1498.

Mizuno S, Ishizaki T, Toga H, Sakai A, Isakova J, Taalaibekova E, Baiserkeev Z, Kojonazarov B, and Aldashev A. (2015). Endogenous asymmetric dimethylarginine pathway in high altitude adapted yaks. Biomed Res Int 2015:196904.

Nicholson TB, Chen T, and Richard S. (2009). The physiological and pathophysiological role of PRMT1-mediated protein arginine methylation. Pharmacol Res 60:466-474.

Penaloza D, and Arias-Stella J. (2007). The heart and pulmonary circulation at high altitudes: Healthy highlanders and chronic mountain sickness. Circulation 115:1132-1146.

Reeves JT, and Leon-Velarde F. (2004). Chronic mountain sickness: Recent studies of the relationship between hemoglobin concentration and oxygen transport. High Alt Med Biol 5:147-155.

Reimann M, Schutte AE, Malan NT, Schwarz PE, Benndorf RA, Schulze F, and Boger RH. (2007). Asymmetric dimethylarginine is associated with parameters of glucose metabolism in Caucasian but not in African women from South Africa. Exp Clin Endocrinol Diabetes 115:600-605.

Richalet JP, Donoso MV, Jimenez D, Antezana AM, Hudson C, Cortes G, Osorio J, and Leon A. (2002). Chilean miners commuting from sea level to $4500 \mathrm{~m}$ : A prospective study. High Alt Med Biol 3:159-166.

Roach RC, Bartsch P, Hackett PH, and Oelz O. (1993). The Lake Louise Acute mountain sickness scoring system. In: Hypoxia and Mountain Medicine. Queen City Press, Burlington, VT. pp. 272-274.

Schneider JC, Blazy I, Dechaux M, Rabier D, Mason NP, and Richalet JP. (2001). Response of nitric oxide pathway to Larginine infusion at the altitude of $4,350 \mathrm{~m}$. Eur Respir J 18:286-292.

Schulze F, Maas R, Freese R, Schwedhelm E, Silberhorn E, and Boger RH. (2005). Determination of a reference value for $\mathrm{N}(\mathrm{G}), \mathrm{N}(\mathrm{G})$-dimethyl-L-arginine in 500 subjects. Eur J Clin Invest 35:622-626.

Schwedhelm E, Maas R, Tan-Andresen J, Schulze F, Riederer U, and Boger RH. (2007). High-throughput liquid chromatographic-tandem mass spectrometric determination of arginine and dimethylated arginine derivatives in human and mouse plasma. J Chromatogr B Analyt Technol Biomed Life Sci 851:211-219.

Schwedhelm E, Tan-Andresen J, Maas R, Riederer U, Schulze F, and Boger RH. (2005). Liquid chromatography-tandem mass spectrometry method for the analysis of asymmetric dimethylarginine in human plasma. Clin Chem 51:12681271.

Schwedhelm E, Xanthakis V, Maas R, Sullivan LM, Schulze F, Riederer U, Benndorf R, Boger RH, and Vasan R. (2009). Asymmetric dimethylarginine reference intervals determined with liquid chromatography-tandem mass spectrometry: Results from the Framingham offspring cohort. Clin Chem 55: 1539-1545.

Scott J, Duongh M, Young A, Subbarao P, Gauvreau G, and Grasemann H. (2014). Asymmetric dimethylarginine in 
chronic obstructive pulmonary disease (ADMA in COPD). Int J Mol Sci 15:6062-6071.

Scott JA, North ML, Rafii M, Huang H, Pencharz P, Subbarao P, Belik J, and Grasemann H. (2011). Asymmetric Dimethylarginine Is Increased in Asthma. Am J Respir Crit Care Med 184:779-785.

Semenza GL. (2011). Oxygen sensing, homeostasis, and disease. N Engl J Med 365:537-547.

Siqués P, Brito J, Leon-Velarde F, Barrios L, Cruz JJDL, Lopéz V, and Herruzo R. (2006). Time course of cardiovascular and hematological responses in rats exposed to chronic intermittent hypobaric hypoxia $(4600 \mathrm{~m})$. High Alt Med Biol 7: 72-80.

Tran CT, Leiper JM, and Vallance P. (2003). The DDAH/ ADMA/NOS pathway. Atheroscler Suppl 4:33-40.

Vallance P, Leone A, Calver A, Collier J, and Moncada S. (1992). Accumulation of an endogenous inhibitor of nitric oxide synthesis in chronic renal failure. Lancet 339:572-575.
Zubieta-Calleja GR, Paulev PE, Zubieta-Calleja L, and ZubietaCastillo G. (2007). Altitude adaptation through hematocrit changes. J Physiol Pharmacol 58 Suppl 5:811-818.

Address correspondence to: Nicole Lüneburg, PhD Department of Clinical Pharmacology and Toxicology University Medical Center Hamburg-Eppendorf Martinistrasse 52 20246 Hamburg Germany

E-mail: n.lueneburg@uke.de

Received October 25, 2016; accepted in final form March 16, 2017. 